Journal of Advanced Research in Fluid Mechanics and Thermal Sciences

Journal homepage: www.akademiabaru.com/arfmts.html ISSN: 2289-7879

\title{
Numerical Investigation of Air Movement on Laboratory Scale Psychrometric Chamber
}

\author{
Elang Pramudya Wijaya ${ }^{1}$, Ardiyansyah Saad Yatim ${ }^{1, *}$ \\ 1 Department of Mechanical Engineering, Faculty of Engineering, Universitas Indonesia, Depok 16424, Indonesia
}

\begin{tabular}{|c|c|}
\hline ARTICLE INFO & ABSTRACT \\
\hline $\begin{array}{l}\text { Article history: } \\
\text { Received } 3 \text { February } 2021 \\
\text { Received in revised form } 6 \text { April } 2021 \\
\text { Accepted } 8 \text { April } 2021 \\
\text { Available online } 16 \text { July } 2021\end{array}$ & $\begin{array}{l}\text { Higher energy demands in favorable energy prices increasing people's affordability of } \\
\text { the cooling devices, causing most building and residential areas to wear air } \\
\text { conditioning systems. Higher energy saving, efficiency, and eco-friendly equipment } \\
\text { have become a challenge for manufacturers and researchers. Also, Indonesia's } \\
\text { government rules the energy efficiency by SKEM (Minimum Standard of Energy } \\
\text { Performance) by air conditioning equipment's labeling. In this study, the use of } \\
\text { perforated ceiling was selected due to the excellent air distribution performance of the } \\
\text { panels. This study analyzes the air circulation distribution (air loop) in a psychometric } \\
\text { chamber using computational fluid dynamics (CFD), especially placing the air } \\
\text { conditioner test unit. The numerical studies are performed with porous media models. } \\
\text { A CFD model was used to analyze the air distribution in the psychrometric chamber. } \\
\text { The simulation results show that the higher value of C1 resulted in a higher value of } \\
\text { velocity. Furthermore, the pressure drop in the test chamber did not show any } \\
\text { significant influence. In all cases, the influence of C1 value did not significantly affect } \\
\text { the air movement in the test chamber. }\end{array}$ \\
\hline
\end{tabular}

\section{Introduction}

In Indonesia, total energy demand is growing around seven percent each year, according to the Green Policy Paper by the Ministry of Finance Republic Indonesia [1]. Higher energy demands in favorable energy prices increasing people's affordability of the cooling devices, causing most building and residential areas to wear air conditioning systems [2]. Air conditioning's future depends on local climatic conditions, population, people's income growth, electricity equipment prices, and energy efficiency and performance [3]. In developed countries, increased energy consumption was seen in the data of growing demand of HVAC system to achieve thermal comfort [4]. With 263.9 million of the total population and the annual average growth rate reached $1.31 \%$, Indonesia's electrification rate raised from $52 \%$ in 2001 to $95 \%$ in 2017 , which resulted in $6.31 \%$ of the annual electricity consumption rate [5]. Thermal comfort is an important factor in indicating a person's satisfaction with the surrounding environment [6], [7]. Therefore, the government is adjusting the energy needs

\footnotetext{
* Corresponding author.

E-mail address: ardiyansyah@eng.ui.ac.id
}

https://doi.org/10.37934/arfmts.84.2.8291 
due to the increased use of air conditioners by building additional power plants to satisfy extra electricity demands. Higher energy saving, efficiency, and eco-friendly equipment have become a challenge for manufacturers and researchers. Also, Indonesia's government rules the energy efficiency by SKEM (Minimum Standard of Energy Performance) by air conditioning equipment's labeling [8]. One of the tests is energy efficiency rating, which needs to be done in a psychrometric chamber. A psychrometric chamber is a chamber in which the room's temperature and humidity are controlled [9].

The improvement in the air distribution system in the psychrometric chamber needs to be uniform [10]. The study showed that non-uniform air velocity and temperature distribution lead to a measurement failure. ASHRAE Standard 41.1 [11] recommends adding several mixers for nonuniform airflow to obtain heat balance. ASHRAE Standard 41.2 [12] suggests that the airflow measurement procedures need straighteners as a tool to produce uniform flow in measurements. In this study, the use of a perforated ceiling was selected due to the excellent air distribution performance of the panels. The air looped was supplied to ducting and distributed along with the clearance and the perforated ceiling. The perforated ceiling characteristic makes them suitable to act as a diffuser [13].

Furthermore, the large area of the air diffuser makes it possible to distribute the air ventilation compared to traditional mixing ventilation systems. Moreover, the diffuser has a lower pressure drop in the system, reducing air movement energy [13]. Despite several advantages in using perforated panels in the office or classroom, there is a need for the panel investigation on the psychrometric chamber application. Thus, this study analyzes the air circulation distribution (air loop) in a psychometric chamber using computational fluid dynamics (CFD), especially placing the air conditioner test unit.

\section{Methodology}

\subsection{Computational Domain}

CFD simulations were performed on the computational domain shown in Figure 1. The volume consisted of a room with dimensions of $(W \times L \times H) 3 \mathrm{~m} \times 3.9 \mathrm{~m} \times 2.9 \mathrm{~m}$. The inlet to the plenum was a duct with the sizes listed in Figure 2 with the dimensions of the inlet $(\mathrm{W} \times \mathrm{H}) 0.35 \mathrm{~m} \times 1.75 \mathrm{~m}$. The outlet configuration was in the bottom section of the Air Handling Unit (AHU); respectively, it was the AHU inlet section. This study did not perform inside of the AHU but limited just in the chamber. The air supply through the inlet was assumed to have a uniform profile. A ventilation duct was placed above the Air Handling Unit specified in Table 1. The inlet and outlet were built with rectangular shapes to match the actual conditions to generate the high-quality mesh.

A 3D geometry was developed to display the flow characteristic inside the chamber. The CFD simulations require a suitable model to specify the airflow through the diffuse ceiling panels. This CFD model also requires an appropriate turbulence model for solving the airflow and the temperature distribution in a closed space. The chamber consists of an Air Handling Unit and the perforated panels. The modeled Air Handling Unit is displayed in Figure 1(a) and the 3D visualization in Figure 1(b). The initial inlet velocity was set to $2 \mathrm{~m} / \mathrm{s}$, which corresponds to the JATL standard requirement. 


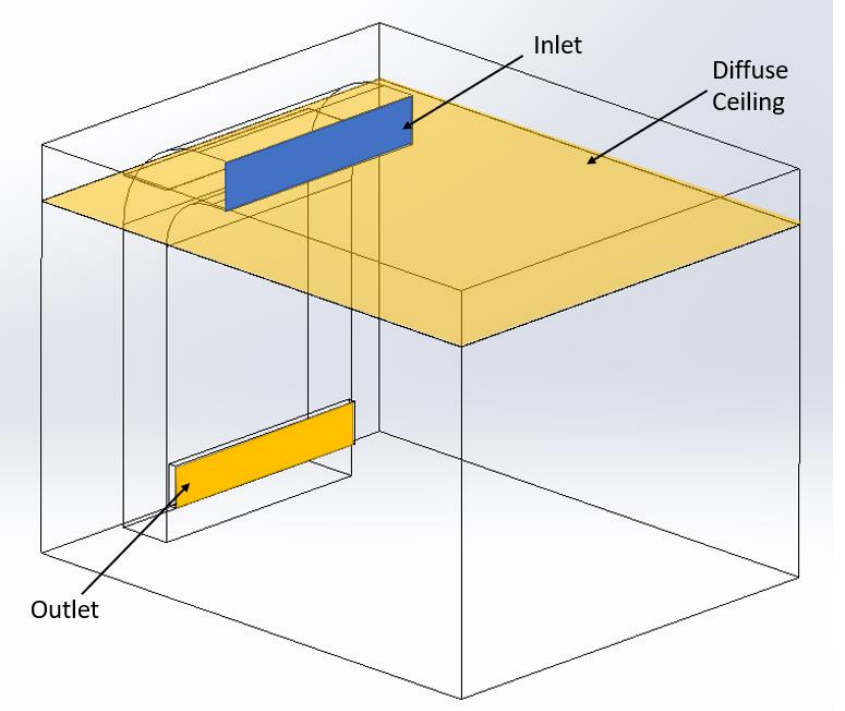

(a)

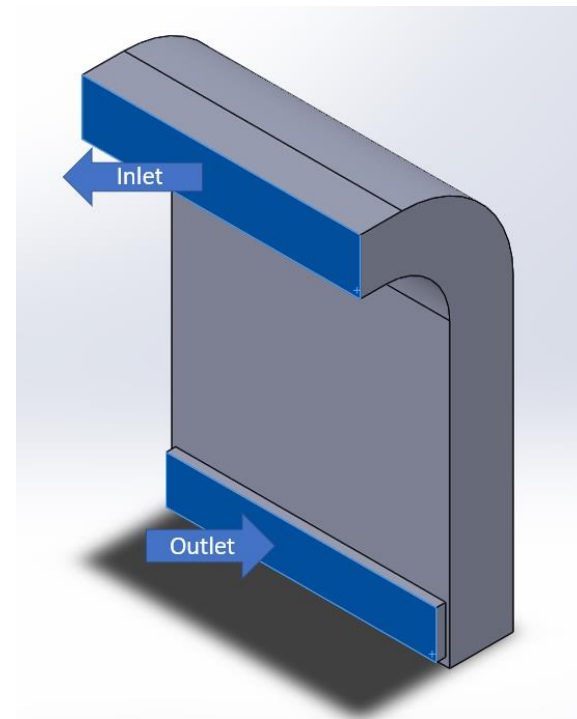

(b)

Fig. 1. (a) Geometrical model of the psychrometric chamber, (b) Air Handling Unit

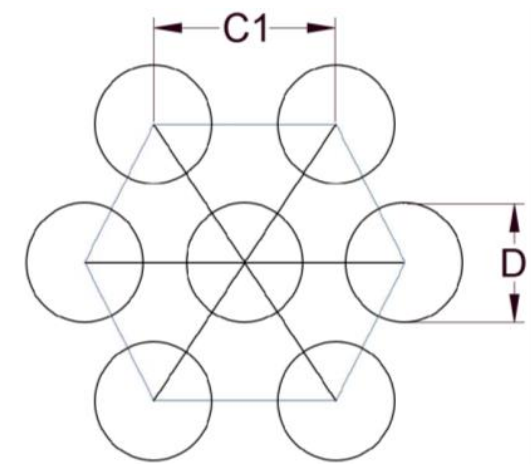

Fig. 2. DCV Hole Dimension

The diffuse ceiling panels used in this study had a porous model of air diffusion. Since it was impossible to simulate the porous design in the CFD modeling, a porous media model was chosen to prevent unnecessary mesh and increase the time efficiency. The porous media model was developed based on Darcy-Forchheimer Law which adding a momentum source term in the equation (ANSYS 2009). When the flow goes through the porous media, the viscous term is dominant with very low velocity. Nevertheless, if the velocity were high-velocity flow, the inertial effects would take place. The governing equation can be expressed below

$\Delta p=-\left(\frac{\mu}{\alpha} v+C_{2} \frac{1}{2} \rho v^{2}\right)$

where $1 / \alpha$ is the viscous resistance coefficient and the pressure jump coefficient $C_{2}$ were determined by the equivalent perforation diameter then $v$ is the velocity normal to the porous face, and $\Delta_{m}$ is the thickness of the medium. The use of perforated panels affects the porous medium equation. A porous model has been designed earlier to obtain the pressure jump coefficient and face permeability coefficient. The dimensions of the hole are shown in Table 1. 
Table 1

C1 Lengths variation $(\mathrm{m})$

\begin{tabular}{llll}
\hline $\mathrm{C} 1_{1}$ & $\mathrm{C}_{2}$ & $\mathrm{C} 1_{3}$ & $\mathrm{C}_{14}$ \\
\hline 0.02 & 0.04 & 0.06 & 0.08 \\
\hline
\end{tabular}

The airflow through diffuse ceiling panels could be laminar because of the very low velocity. However, the flow could be turbulent because of higher velocity from the inlet region. Chen et al., recommends the Re-normalized group (RNG) of $k-\varepsilon$ turbulence model for indoor environment simulation [14]. Kuwata et al., proved that $k-\varepsilon$ turbulence model prediction accuracy is satisfactory for porous media zone [15].

Several parameters were set during the computational simulation, such as the inlet velocity set into $2 \mathrm{~m} / \mathrm{s}$ with the 0 Pa pressure outlet, which indicates pressure differences between the room pressure with the outlet pressure and the density of fluid which is air density $1,2 \mathrm{~kg} / \mathrm{m}^{3}$ and the viscosity of air in the ambient temperature which showed in the Table 2.

Table 2

Analysis Parameter

\begin{tabular}{ll}
\hline Parameter & Values \\
\hline Inlet velocity $(V)$ & $2 \mathrm{~m} / \mathrm{s}$ \\
Pressure outlet & $0 P a$ \\
Density of fluid $(\rho)$ & $1,2 \mathrm{~kg} / \mathrm{m}^{3}$ \\
Viscosity & $0.0000179 \mathrm{~kg} / \mathrm{m}$ \\
\hline
\end{tabular}

\subsection{Grid Convergence Index}

In the CFD, deciding the mesh is an important factor to predict and minimalize the errors. A massive amount of mesh may not be a good idea due to the immense of computational power needed [16]. Because of that, this study uses the mesh independency method to define the necessary mesh to this simulation. This study uses Richardson extrapolation by using Grid Convergence Index $(\mathrm{GCl})$. This was chosen due to the need of accurate mesh and to prevent time consumption in simulations. Calculating spatial convergence of a simulation is a method for determining discretization error in the simulation [17]. It is currently the most practice method to predict numerical uncertainty and improve computational efficiency [18]. This method requires several mesh variations to predict which mesh is effective for the case.

Five different mesh are created in order to examine the mesh independent solution based on predicting the pressure in the model. This method was performed to predict the mesh using Grid Refinement Ratio as

$r=\left(\frac{N_{\text {fine }}}{N_{\text {coarse }}}\right)^{\frac{1}{d}}$

where, $N$ is the number of grid points that are used for the grid, and $d$ is the dimension of the model. This simulation is computed on five different number of meshes with a fine mesh setting. Then, the Grid Convergence Index $(\mathrm{GCl})$ was calculated using the expression

$G C I_{a b}=H\left|\frac{1}{p_{a}} \frac{p_{b}-p_{a}}{r_{a b}{ }^{K}-1}\right| \times 100 \%$ 
where $H$ is safety factor of 1.25 , and $r$ is the grid refinement ratio which is represented to the equation below

$r_{a b}=\left(\frac{M_{a}}{M_{b}}\right)^{0.5}$

The $\mathrm{GCl}$ calculation on this study is shown in Table 3, resulting from average pressure slightly under the DCV. The comparison indicates that the calculation with the 1.2 million number of mesh was less than $0.2 \%$. The increase in elements from 803.291 mesh elements to 1.2 million mesh elements did not significantly improve the result but cost more computing time. Consequently, this study's numerical uncertainty was $0.65 \%$, with a number of elements of about 800.000 elements.

Table 3

\begin{tabular}{llll} 
Independency Test Result & & \\
\hline Normalized Grid Spacing & Number of Elements & Pressure $[\mathrm{Pa}]$ & $\mathrm{GCl}$ \\
\hline 1.74 & 424684 & 36.89 & - \\
1.43 & 628699 & 32.54 & $1.54 \%$ \\
1.26 & 803291 & 33.17 & $0.65 \%$ \\
1.09 & 1073865 & 33.81 & $0.45 \%$ \\
1 & 1293035 & 33.89 & $0.14 \%$ \\
0 & Infinite & 33.93 & - \\
\hline
\end{tabular}

\subsection{Simulation Setup}

The computational method was using ANSYS ${ }^{\circledR}$ FLUENT 18.1 ${ }^{\mathrm{TM}}$. The calculation used an isothermal unsteady Reynolds-averaged Navier-Stokes with a SIMPLE pressure velocity couplings and a second order upwind spatial discretization. This method is preferred to ensure a stable numerical performance of the calculation [13]. The standard $k-\varepsilon$ model is also used in this simulation due to its reasonable accuracy in simulating flow characteristics with applications ranging from industrial to environmental flows. The governing equations for $\mathrm{k}-\varepsilon$ turbulence models are available in Eq. (5) and Eq. (6)

$\frac{\partial(\rho k)}{\partial t}+\nabla(\rho k u)=\nabla\left(\mu_{1} / \rho k \nabla k\right)+2 \mu, E_{i J} E_{i J}-\rho \epsilon$

$\frac{\partial(\rho k)}{\partial t}+\nabla\left(\frac{\mu_{t}}{\rho k} \nabla_{\epsilon}\right)+C_{l \varepsilon} \frac{\varepsilon}{k} 2 \mu, E_{i J} E_{i j}-C_{2 \varepsilon} \frac{\varepsilon^{2}}{k}$

The boundary condition for the inlet was $2 \mathrm{~m} / \mathrm{s}$ velocity inlet, and for the outlet was set to 0 gauge pressure outlet. A constant initial air density was used $\left(\rho_{\text {air }}=1225 \mathrm{~kg} / \mathrm{m}^{3}\right)$. The initial temperature of the chamber was $284 \mathrm{~K}$, this setup was referred to the air conditioner minimum outlet temperature. The simulations were conducted in the transient state with the set time step $\Delta t=$ $0.05 s$ and 5000 iterations.

From the $\mathrm{GCl}^{\prime}$ s calculation, five mesh size were estimated to find the suitable mesh size. From the mesh variations, the chosen mesh was $800 \mathrm{k}$ elements as seen in the Figure 3. 


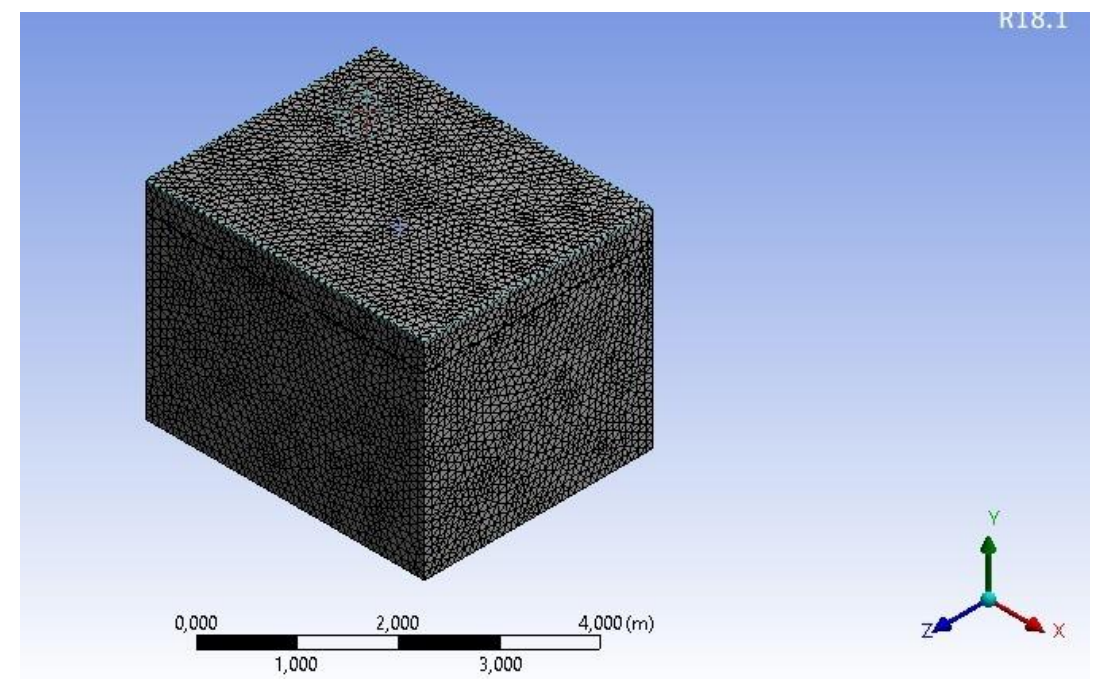

Fig. 3. Mesh number of elements about 800.000 elements

\section{Results}

\subsection{Results}

This section will present the test chamber's computed airflow pattern along with the velocity contour and the streamline. The objective is to analyzes the air circulation distribution (air loop) in a psychometric chamber, especially for placing the air conditioner test unit. The results are presented as the average velocity in a plane that has been determined. Table 4 display the overview of the value calculated in the simulation. Table 4 shows the value of the average velocity component and the pressure drop along the determined plane. This option was due to the different diffusion rates of the perforated ceiling. It can figure out how the air velocity was behaving through the diffuser while the inlet air was constantly going through the plenum.

\section{Table 4}

The calculated value of air distribution and pressure drop along with the perforated panels

\begin{tabular}{lll}
\hline Variations & Average velocity $(\mathrm{m} / \mathrm{s})$ & Pressure Drop $(\mathrm{Pa})$ \\
\hline $\mathrm{C} 1_{1}$ & 0.86 & 5.40 \\
$\mathrm{C} 1_{2}$ & 0.88 & 5.44 \\
$\mathrm{C}_{3}$ & 0.91 & 5.49 \\
$\mathrm{C}_{4}$ & 1.01 & 5.52 \\
\hline
\end{tabular}

The pressure drop was calculated from the difference between the inlet and the outlet pressure value. The average velocity fields are shown in Figure 4 to Figure 7 . The averaged velocity reported was from the highest average velocity of all time steps of the simulation. The chosen parameter referring to the JATL [17] standard with the air velocity conditions must be below $2.5 \mathrm{~m} / \mathrm{s}$. In all cases, the average velocity calculated in a plane that is located $0.01 \mathrm{~m}$ below the perforated ceiling, in the middle of the room, and the plane in the middle of the outlet surface. The location was chosen to measure and analyze the leaving airflow's behavior through the panels and the room itself. The contour shows the velocity values on three horizontal planes, while on the right side, a more detailed contour of the top plane is shown for each of the cases.

Figure $8(a)$ to Figure $8(d)$ show each of $C 1$ variations' vector, and the vector represents the flow from the inlet duct to the outlet. The XZ plane in the middle of the chamber was chosen because it 
can represent the airflow in the chamber. Furthermore, the plane was placed respectively at the origin and roughly cutting the inlet and the outlet flow.
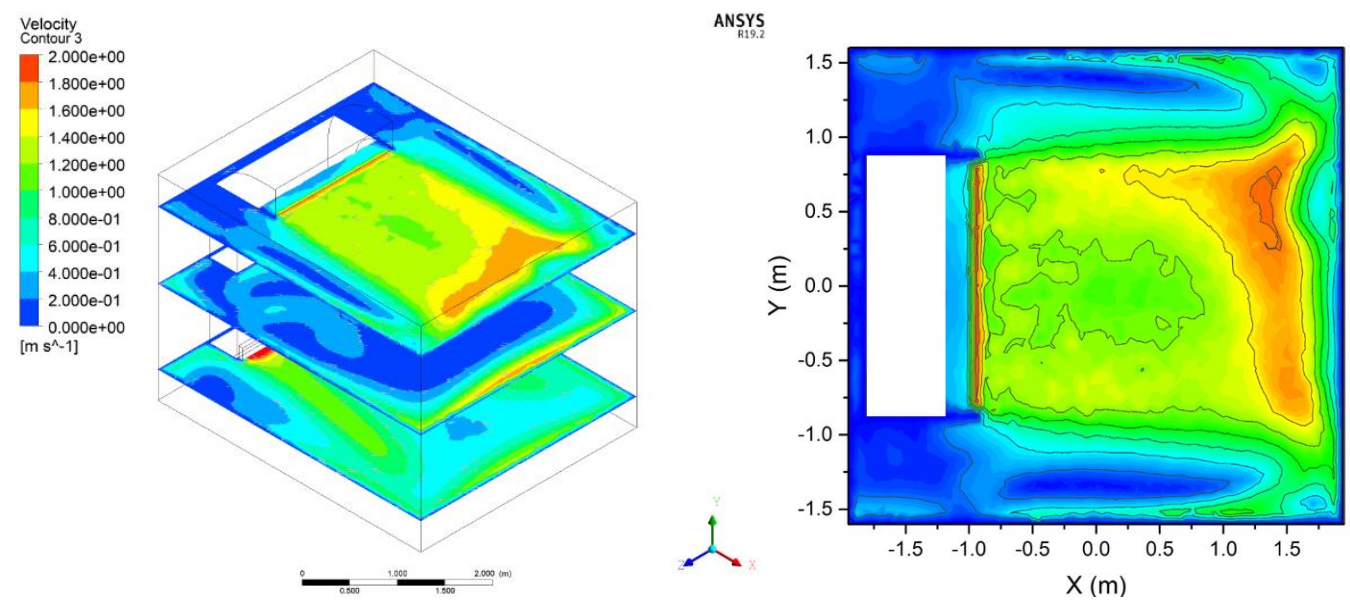

Velocity $(\mathrm{m} / \mathrm{s})$

Fig. 4. Velocity contour of three horizontal plane (left), the top plane below the ceiling (right) in $\mathrm{C}_{1}$ configuration
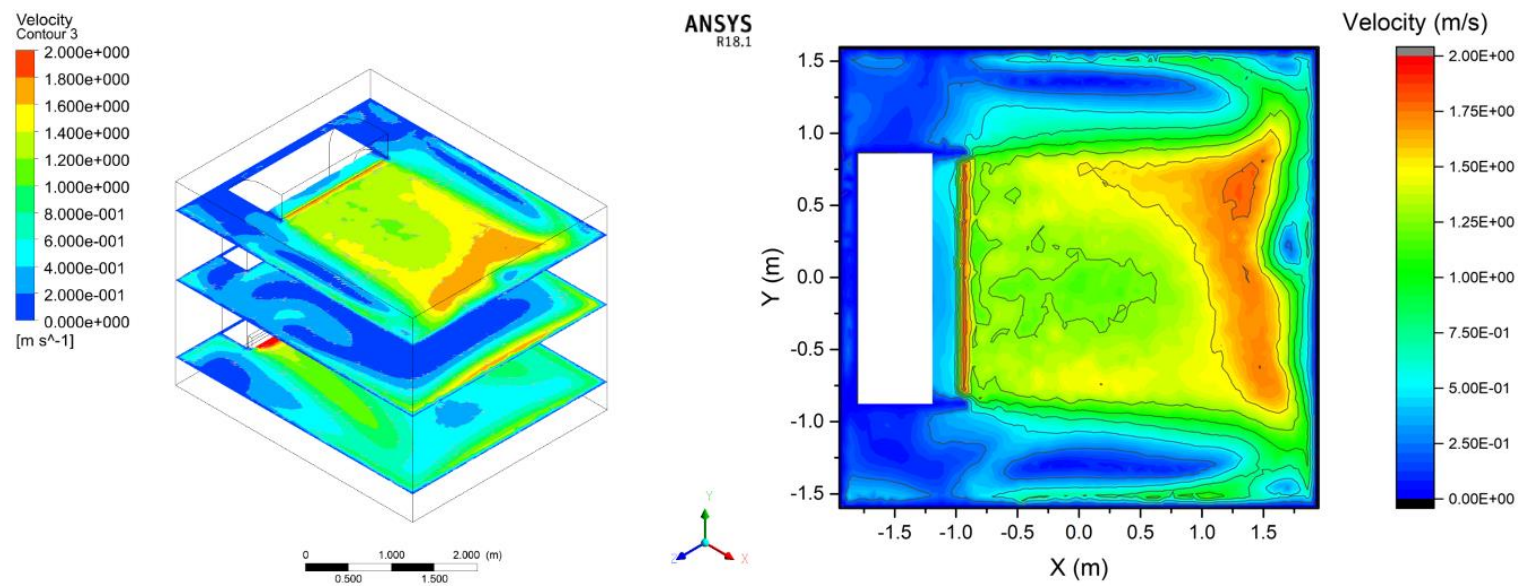

Fig. 5. Velocity contour of three horizontal plane (left), the top plane below the ceiling (right) in $\mathrm{C}_{2}$ configuration
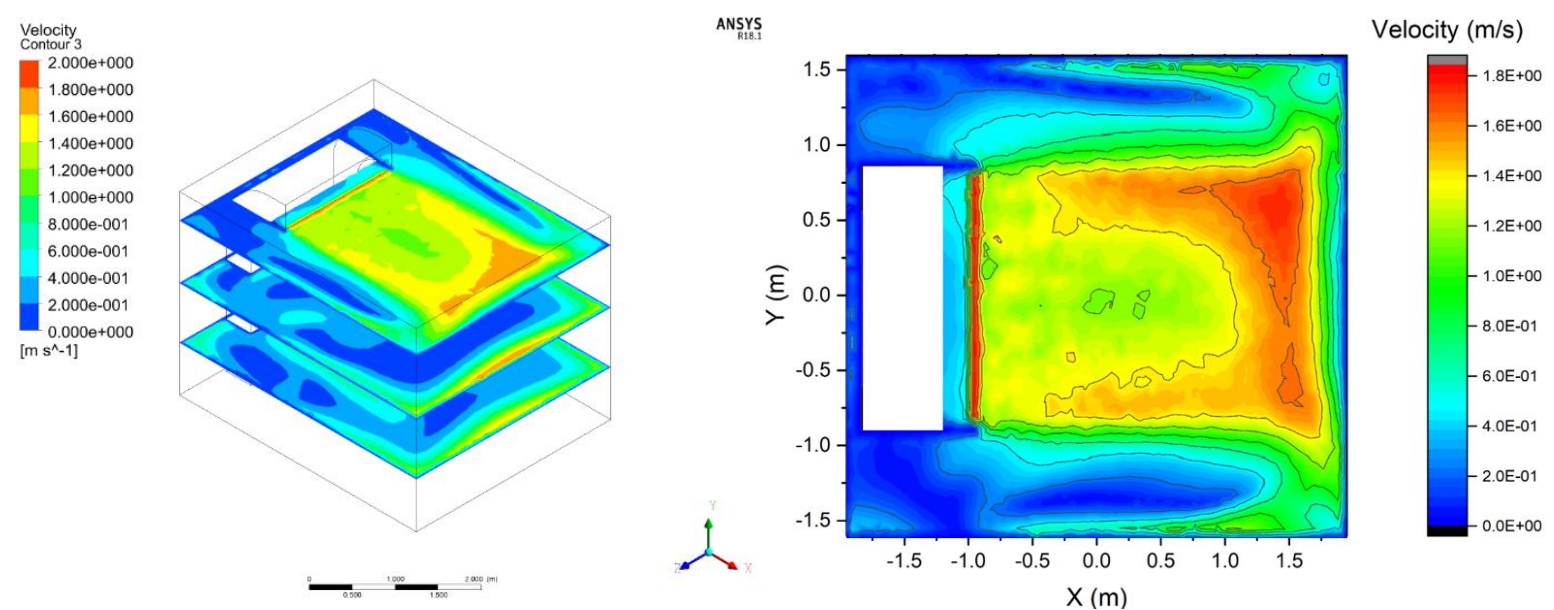

Fig. 6. Velocity contour of three horizontal plane (left), the top plane below the ceiling (right) in $\mathrm{C}_{3}$ configuration 

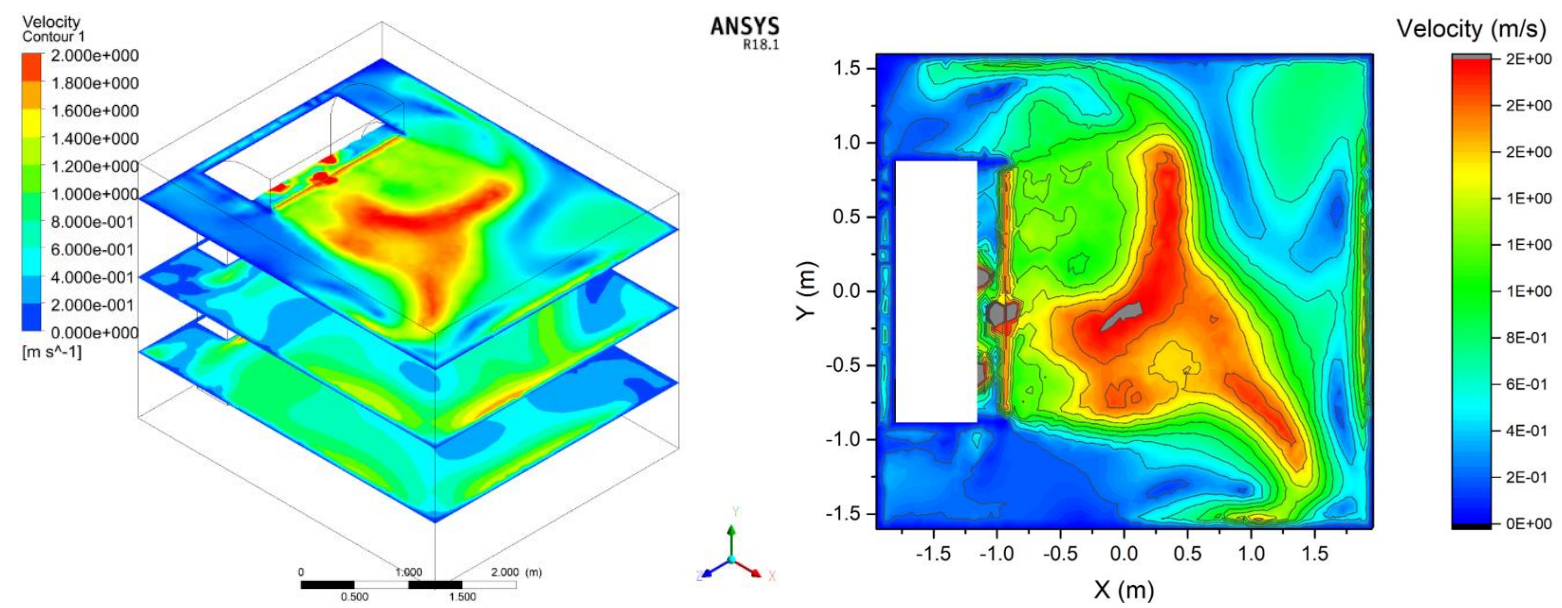

Fig. 7. Velocity contour of three horizontal plane (left), the top plane below the ceiling (right) in $\mathrm{C1}_{4}$ configuration

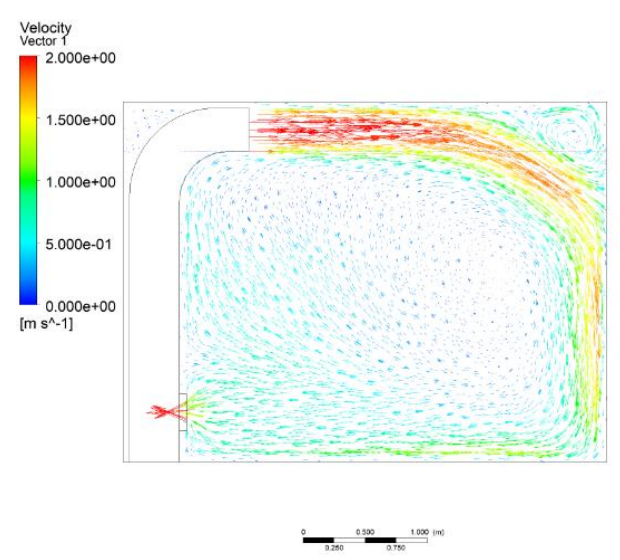

(a)

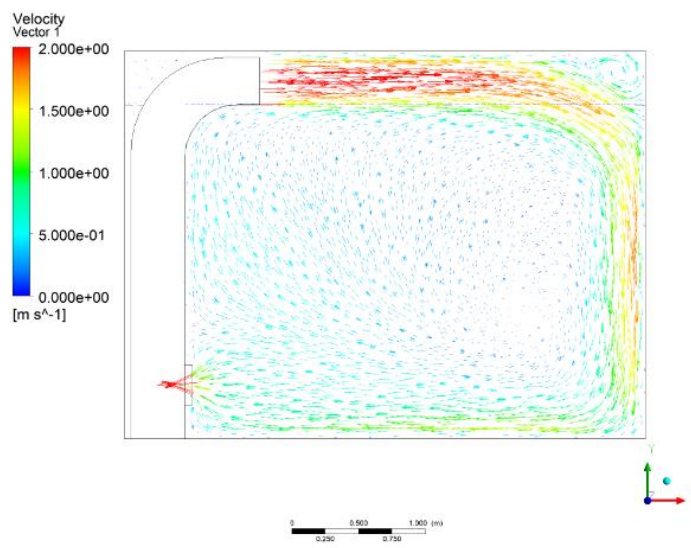

(c)

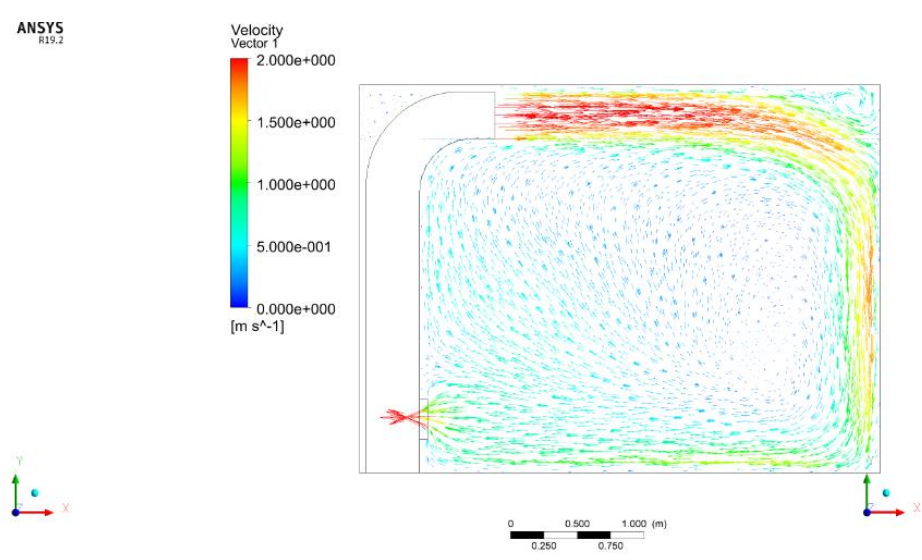

(b)

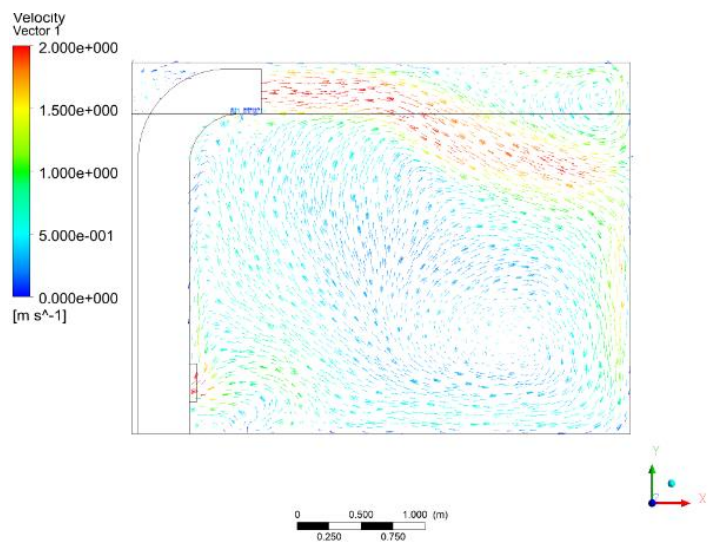

(d)

Fig. 8. The velocity vector of the middle of the room (a) $\mathrm{C1}_{1}$, (b) $\mathrm{C1}_{2}$, (c) $\mathrm{C1}_{3}$, (d) $\mathrm{C1}_{4}$

\subsection{Discussions}

As we see in Table 4, the average velocity always reached a higher value when the $C 1$ value is higher configurations. It was expected because of a different value of pressure drop in each configuration. The influence of higher pressure at the plenum, causing the air to be compressed and resulting in a higher average velocity in the first plane after the panels. The maximum pressure in the $\mathrm{C1}_{4}$ was occurring due to the lowest quantity of holes in the perforated panels. This phenomenon 
was causing the plenum to have a higher value of pressure drop. It is interesting to state that a significant difference in pressure could be seen for configurations with different $\mathrm{C} 1$ distances. This evidence suggested that the $\mathrm{C} 1$ distance in the perforated panels influenced the greater extent of pressure in the plenum. Furthermore, the simulations' maximum air velocity was below the limit of JATL standard for psychrometric chamber measurements [19].

The ceiling contours in Figure 4 to Figure 7 showed the room's velocity distribution and the perforated panels. A significant difference of each configuration was the flow of the $\mathrm{C}_{4}$ was slightly distributed along the panels first, then the airflow starts diffusing through the panels. This suggested that the choice of $\mathrm{C} 1$ distance influence the performance of perforated panels. Furthermore, as seen in the second plane, the velocity distribution was higher at the $X>1.5 \mathrm{~m}$, which means the high velocity of the air inlet was pushing through the wall then diffuse around the wall of the psychrometric chamber. However, the low-velocity region of the middle sections did not influence the air conditioning testing. This was because the air conditioner inlet location was near the wall, which has the higher velocity contours.

The influence of the $\mathrm{C} 1$ distance could be seen on the distribution on airflow after it was going through the perforated panels. The flow patterns were comparable. From the vectors in Figure 8 we can see the vortex inside the chamber. This was expected because the flow was going through the perforated panels perpendicular to the ceiling panels. The airflow did not directly flow to the outlet area and tended to circulate around the chamber itself. The flow pattern may have an effect to the performance of the psychrometric chamber, but it was not an objective in this study. This study's importance was the effects of the $\mathrm{C} 1$ distance to the air distribution in the psychrometric chamber. Figure 4 to Figure 7 shown that the direct air velocity from the perforated panels resulted in a direct impact on the air conditioner test unit's inlet.

\section{Conclusions}

This perforated ceiling simulations have shown the diffuse ceiling ventilation character that plays a significant role in distributing the air to the chamber. The perforated ceiling significantly decreased the air inlet's velocity and ensured the lower velocity on the air conditioning test chamber.

The comparison between the $\mathrm{C} 1$ distance showed that although the increasing value of $\mathrm{C} 1$ did not resulted in a significant increase in air velocity on the test chamber. The velocity was increasing along with the rising value of $\mathrm{C} 1$. Furthermore, the pressure drop in the test chamber did not show any significant influence. Even though the pressure drop was not showing much effect to the test chamber, the test chamber's geometry shown an air distribution on the $\mathrm{C}_{1}$ configuration plenum before it was going through the perforated ceiling. This phenomenon also occurs in the previous work by Nocente et al., [13] in the chessboard configuration DCV. The geometry of the perforated panels produces a significant effect on the air distribution in the test chamber.

\section{Acknowledgment}

This study is supported by Universitas Indonesia research program.

\section{References}

[1] Fuadi, Zulfa, Ardiyansyah Yatim, Rachmah Rizky, Nyayu Aisyah, Idrus Alhamid, Budihardjo Budihardjo, and Nandy Putra. "Chiller performance study with refrigerant R290." In AIP Conference Proceedings, vol. 2062, no. 1, p. 020061. AIP Publishing LLC, 2019. https://doi.org/10.1063/1.5086608

[2] Biddle, Jeff. "Explaining the spread of residential air conditioning, 1955-1980." Explorations in Economic History 45, no. 4 (2008): 402-423. https://doi.org/10.1016/j.eeh.2008.02.004

[3] Santamouris, Mat. "Cooling the buildings-past, present and future." Energy and Buildings 128 (2016): 617-638. 
https://doi.org/10.1016/i.enbuild.2016.07.034

[4] Muhieldeen, M. W., and Y. C. Kuang. "Saving Energy Costs by Combining Air-Conditioning and Air-Circulation using CFD to Achieve Thermal Comfort in the Building." Journal of Advanced Research in Fluid Mechanics and Thermal Sciences 58, no. 1 (2019): 84-99.

[5] Lee, Chui Ying, Shinji Kaneko, and Ayyoob Sharifi. "Effects of building types and materials on household electricity consumption in Indonesia." Sustainable Cities and Society $54 \quad$ (2020): 101999. https://doi.org/10.1016/i.scs.2019.101999

[6] Putra, Nandy, Evi Sofia, and B. Ali Gunawan. "Evaluation of Indirect Evaporative Cooling Performance Integrated with Finned Heat Pipe and Luffa Cylindrica Fiber as Cooling/Wet Media." Journal of Advanced Research in Experimental Fluid Mechanics and Heat Transfer 3, no. 1 (2021): 16-25.

[7] Hassan, Zulkurnain, Mohd Suffian Misaran, and Nancy Julius Siambun Misran. "Experimental Performance Analysis of a Direct Evaporative Cooler." Journal of Advanced Research Design 67, no. 1 (2020): 1-8.

[8] Widodo, Taufan, Ardiyansyah Yatim, M. Alhamid, and A. Brantyopati. "Design and construction of air flow measurement device in psychrometric chamber for air conditioner energy labeling." In AIP Conference Proceedings, vol. 2230, no. 1, p. 050005. AIP Publishing LLC, 2020. https://doi.org/10.1063/5.0002288

[9] Brantyopati, A., Ardiyansyah Yatim, Muhammad Idrus Alhamid, and Taufan Widodo. "Design and construction of temperature measurement in psychrometric chamber for split air conditioner testing and energy labelling." In AIP Conference Proceedings, vol. 2227, no. 1, p. 020028. AIP Publishing LLC, 2020.

[10] Wile, D. D. "Air flow measurement in the laboratory." Journal of the ASRE (1947): 515-521.

[11] Standard, A. S. H. R. A. E. "Standard 41.1-1986, Standard method for temperature measurement." American Society of Heating, Refrigerating and Air-Conditioning Engineers, Inc., Atlanta, GA (1986).

[12] Standard, A. S. H. R. A. E. "Standard 41.2-1991, Standard Method for Laboratory Airflow Measurement." American Society of Heating, Refrigerating and Air-Conditioning Engineers, Inc., Atlanta, GA (1991).

[13] Nocente, Alessandro, Tufan Arslan, Steinar Grynning, and Francesco Goia. "CFD Study of Diffuse Ceiling Ventilation through Perforated Ceiling Panels." Energies 13, no. 8 (2020): 1995. https://doi.org/10.3390/en13081995

[14] Chen, Qingyan. "Comparison of different k- $\varepsilon$ models for indoor air flow computations." Numerical Heat Transfer, Part B Fundamentals 28, no. 3 (1995): 353-369. https://doi.org/10.1080/10407799508928838

[15] Kuwata, Yusuke, Kazuhiko Suga, and Yota Sakurai. "Development and application of a multi-scale k- $\varepsilon$ model for turbulent porous medium flows." International Journal of Heat and Fluid Flow 49 (2014): 135-150. https://doi.org/10.1016/i.ijheatfluidflow.2014.02.007

[16] Almohammadi, K. M., D. B. Ingham, L. Ma, and M. Pourkashan. "Computational fluid dynamics (CFD) mesh independency techniques for a straight blade vertical axis wind turbine." Energy 58 (2013): $483-493$. https://doi.org/10.1016/j.energy.2013.06.012

[17] Phillips, Tyrone S., and Christopher J. Roy. "Richardson extrapolation-based discretization uncertainty estimation for computational fluid dynamics." Journal of Fluids Engineering 136, no. 12 (2014). https://doi.org/10.1115/1.4027353

[18] Zlatev, Zahari, Ivan Dimov, István Faragó, and Ágnes Havasi. Richardson extrapolation: practical aspects and applications. Vol. 2. Walter de Gruyter GmbH \& Co KG, 2017. https://doi.org/10.1515/9783110533002

[19] JATL. JATL Training on Air Conditioner Testing. Japan Air Conditioning and Refrigeration Testing Laboratory, 2017. 